\title{
Organizing a functional junctional complex requires specific domains of the Drosophila MAGUK Discs large
}

\author{
Colleen D. Hough, ${ }^{1}$ Daniel F. Woods, ${ }^{2}$ Sangbin Park, and Peter J. Bryant \\ Developmental Biology Center, University of California, Irvine, California 92697-2275 USA
}

\begin{abstract}
Discs large (DIg) was the first identified member of an increasingly important class of proteins called membrane-associated guanylate kinase homologs (MAGUKs), which are often concentrated at cell junctions and contain distinct peptide domains named PDZ1-3, SH3, HOOK, and GUK. DIg is localized at and required for the formation of both septate junctions in epithelial cells and synaptic junctions in neurons. In the absence of DIg epithelia lose their organization and overgrow. We tested the functions of each domain of Dlg in vivo by constructing transgenic flies expressing altered forms of the protein. In the first set of experiments each domain was examined for its ability to correctly target an epitope-tagged DIg to preexisting septate junctions. Based on these results the Hook domain is necessary for localization of the protein to the cell membrane and the PDZ2 is required for restricting the protein to the septate junction. In the second set of experiments each domain was tested for its role in growth regulation and organization of epithelial structure These results show that PDZ1 and GUK are apparently dispensable for function, PDZ2 and PDZ3 are required for growth regulation but not for epithelial structure, and SH3 and HOOK are essential for both aspects of function. The results demonstrate the functional modularity of DIg and clarify the functions of individual MAGUK domains in regulating the structure and growth of epithelial tissue.
\end{abstract}

[Key Words: DIg; MAGUK; PDZ; SH3; guanylate kinase; tumor suppressor; septate junction; Drosophila]

Received August 13, 1997; revised version accepted September 30, 1997.

Components of signal transduction pathways that govern growth and differentiation function in specific subcellular locations to allow cells to respond efficiently to their environment. Proteins involved in the initial steps of many signal transduction pathways are restricted to a defined region of the plasma membrane or more specifically to junctional cell-cell contact sites. Examples include Notch, Delta, cadherins, catenins, Sev/Boss, growth factor receptors, neurotransmitter receptors, and small G proteins (Tomlinson et al. 1987; Fehon et al. 1991; Cagan et al. 1992; Zak and Shilo 1992; Froehner 1993; Kooh et al. 1993; Woods and Bryant 1993; N athke et al. 1994; Oda et al. 1994; A berle et al. 1996; Dodane and Kachar 1996). This localization to specialized membrane regions can be crucial to the function of these proteins. For example, the Rhomboid protein promotes epidermal growth factor receptor (EGF-R) signaling at the apical cell surface during Drosophila embryogenesis and its localized expression is necessary for regulation of EGF-R-dependent differentiation (Sturtevant et al. 1996).

The precise subcellular local ization of proteins can de-

1Present address: Department of Biochemistry and Biophysics, Texas A\&M University, College Station, Texas 77843-2128 USA.

${ }^{2}$ Corresponding author.

E-MAIL dwoods@uci.edu; FAX (714) 824-3571. pend on certain domains, and in some cases, such as the mucin MUC1, more than one domain is required for proper localization (Pemberton et al. 1996). In addition, some proteins become localized by a two-step process; for example in the bacterial chemoreceptor methyl-accepting chemotaxis protein (MCP) the amino terminus is required for membrane targeting and the carboxyl terminus is required for polar localization (Alley et al. 1993).

Members of the MAGUK (membrane-associated guanylate kinase homologs) protein family are often localized at cell junctions and may serve to localize other proteins at those sites. Each M AGUK contains a core of three types of peptide domains in conserved sequential order: (1) PDZ domains [PSD-95, Discs large (DIg), ZOO-1; 1 or 3 copies] have the ability in some MAGUKs to bind and cluster membrane receptors and channel proteins and appear to be involved in subcel lular targeting (Kim et al. 1995, 1996; Kornau et al. 1995; Müller et al. 1995; N iethammer et al. 1996; Tejedor et al. 1997); (2) the SH3 domain (src-homology 3 ) is a protein-protein interaction site that has been suggested to function in targeting signaling components to the membrane (Bar-Sagi et al. 1993; Schlessinger 1994; Cohen et al. 1995); (3) the guanylate kinase-homologous region (GUK) is able to bind the guanine nucleotide GMP, but does not appear to function as a guanylate kinase (Kistner et al. 1995; Hos- 
kins et al. 1996; S.M. Marfatia and A.H. Chishti, pers. comm.). The regi on between the $\mathrm{SH} 3$ and GUK domains (HOOK or I3) shows significant sequence similarity between several MAGUKs and, in hDIg and p55, has been shown to bind certain actin-associated proteins of the protein 4.1/ERM (Ezrin, Radixin, Moesin) superfamily (Lue et al. 1994, 1996; Marfatia et al. 1994, 1996).

The proteins associating with MAGUKs include several that are involved in signal transduction pathways. For example, the Caenorhabditis M AGUK Lin-2 and another junction-associated, PDZ-contai ning protein, Lin7 , are required to localize the Let-23 receptor tyrosine kinase to basal junctions (Kim 1995; Hoskins et al. 1996). The product of the Drosophila tumor suppressor gene dlg [lethal (1)discs-large] is a M AGUK located at the cytoplasmic face of septate junctions (Woods et al. 1996) and is necessary for the formation of these junctions and maintenance of cell apico-basal polarity (Woods and Bryant 1989, 1991; Woods et al. 1996). DIg is required at neuromuscular junctions and epithelial septate junctions for signaling events controlling synaptic vesicle release and cell proliferation, respectively (Woods and Bryant 1991; Budnik et al. 1996) and this requirement probably involves securing signaling components at these junctions. The mammalian MAGUKs PSD-95/SAP-90 and Chapsyn-110 can induce clustering of N-methyl-Daspartate (NMDA) receptors and Shaker-type $\mathrm{K}^{+}$channels in cultured cells, presumably reflecting a MAGUK requirement for localizing these transmembrane molecules to synaptic junctions in vivo (Kim et al. 1995, 1996).

The evol utionary conservation of the MAGUK protein domains PDZs, SH3, HOOK, and GUK suggests that similar mechanisms are invol ved in subcell ular targeting and cytoskel etal organization as well as processes such as proliferation control and synaptic transmission in Drosophila and vertebrates. In fact, a mammalian SAP97 or SAP-102 transgene is abl e to rescue a hypomorphic dlg mutant phenotype, indicating that these MAGUKs are functionally equivalent to DIg (Thomas et al. 1997). Additionally, the mammalian tight junction MAGUK ZO-1 can rescue the extra bristle phenotype caused by a mutation in the Drosophila tamou gene that encodes a ZO-1 homolog located at septate junctions (T akahisa et al. 1996).

In this paper we describe the first functional analysis of the MAGUK domains in vivo. Each domain of DIg was examined for its ability to localize to preexisting septate junctions and for its role in growth regulation and organization of epithelial structure in imaginal discs. The results will help to el ucidate the function of MAGUKs as organizers of cell junctions and ultimately define their role in cell-cell interactions.

\section{Results}

Mapping DIg domains required for subcellular Iocalization

To define the domains responsible for targeting DIg to septate junctions, we analyzed the subcellular location of FLAG epitope-tagged DIg derivatives that were de leted for specific domains (Fig. 1a). To express these DIgFLAG derivatives in wing imaginal discs, the dlg constructs were placed under the control of GAL4 UAS se quences by subcloning into a P-element transformation vector (Brand and Perrimon 1993) and transformed into w embryos. For this series of experiments, the DIgFLAG derivatives were expressed in wild-type animals expressing endogenous DIg. The red-eyed transformants were crossed to a Ptc-driven GAL4 line (Brand and Perrimon 1993) or the 69B GAL4 enhancer trap line (Drosophila Stock Center, Bloomington, IN) to drive expression of the constructs in different spatial patterns. The Ptc driver produces GAL4 at high levels in a stripe adjacent to the anterior/ posterior boundary in the wing disc. The remaining cells, outside of the stripe, provide an internal negative control for antibody specificity. The 69B line produces GAL4 at moderate levels throughout most of the wing disc and, when driving a full-length dlg transgene, has been shown to completely rescue the phenotype of a dlg null mutant (Woods et al. 1996). The GAL4-driven DIg-FLAG proteins were analyzed by Western blot to ensure that the DIg-FLAG fusion proteins were being produced (Fig. 1b). The local ization patterns of the DIg-FLAG fusions in flies containing wildtype DIg were analyzed in wing imaginal discs by confocal microscopy using antibodies against the FLAG tag. The discs were al so stained with rhodamine-phalloidin to detect the band of filamentous actin located at the adherens junctions, just apical to the septate junctions where wild-type DIg is located (Woods et al. 1996).

The original near-full-length dlg-FLAG construct (DIg $\left.{ }^{\Delta 40}-F L A G\right)$ has the FLAG tag inserted at a convenient EcoRI restriction site that results in a protein that is truncated at the carboxyl terminus by 40 amino acids. DIg $^{\text {t40 }}$ FLAG localizes to septate junctions (Fig. 2b), demonstrating that neither the FLAG tag nor the small carboxy-terminal truncation interferes with DIg localization.

To determine which domains have an effect on DIg localization to septate junctions, each domain was removed systematically and the subcellular local ization of the DIg-deletion derivatives analyzed by confocal microscopy. All DIg-FLAG constructs contain the 36 amino-terminal amino acids preceding the first DIg domain, PDZ1. Deleting the first PDZ domain did not affect localization to septate junctions; the DIg ${ }^{\triangle P D Z 1}$ FLAG protein staining appears just basal to apical actin at the level of septate junctions (Fig. 2c). Of the remaining domain-specific deletions, the DIg ${ }^{\triangle P D Z 3}-F L A G$, $\mathrm{DIg}^{\Delta \mathrm{SH}} \mathrm{F}_{-} \mathrm{FAG}$, and $\mathrm{DIg}^{\Delta \mathrm{GUK}}-\mathrm{FLAG}$ proteins target to septate junctions (data not shown) in a pattern similar to the DIg ${ }^{\triangle P D Z 1}$-FLAG protein.

In striking contrast to the previous results, a large de letion eliminating the region from PDZ1 through the SH3 domain, leaving only the HOOK and GUK domains $\left(D I g^{\Delta N 2 / 3}-F L A G\right)$, is distributed throughout the plasma membrane and not enriched at the septate junctions (data not shown). When only the PDZ2 domain is eliminated (DIg $\left.{ }^{\triangle P D Z 2}-F L A G\right)$, the protein localizes to the 
Figure 1. Summary of the DIg-FLAG deletion analyses. (a) Cartoon of the domain-specific DIgdeletion constructs. A $\mathrm{V}$ indicates a deleted domain and a straight line corresponds to the sequences present. The subcellular location of the del etion proteins in wing discs containing endogenous normal DIg protein, and the ability of the deletion proteins to rescue the epithelial structure of wing discs from larvae hemizygous for a genetic null allele dlg $^{\mathrm{m} 52}$ are listed in the columns to the right of each deletion tested. (b) Western blot analysis of the DIg-FLAG proteins from larvae in which the Ptc-driven GAL4 transcriptional activator drives expression of the dlgFLAG deletion constructs. (Lane P) Ptc-driver GAL4 line control; (lane t) $\Delta$ t40-FLAG; (lane 1) $\triangle$ PDZ1-FLAG; (lane 2) $\triangle$ PDZ2-FLAG (69B); (lane 3) $\triangle$ PDZ3-FLAG; (lane S) $\triangle$ SH3-FLAG; (lane H) $\Delta$ HOOK-FLAG; (lane G) $\Delta$ GUK-FLAG; (lane C) $\Delta$ C 1/2-FLAG; (lane 2+) lane containing twice as much $\triangle$ PDZ2-FLAG as lane 2. Deficiency boundaries in base pairs for PDZ1, 109399; PDZ2, 439-756; PDZ3, 1393-1695; SH3, 1810-2001; HOOK, 2002-2340; SH3-HOOKGUK (C1/2), 1810-2805; and PDZ1,2,3-SH3 (N 2/3), 109-2001. a

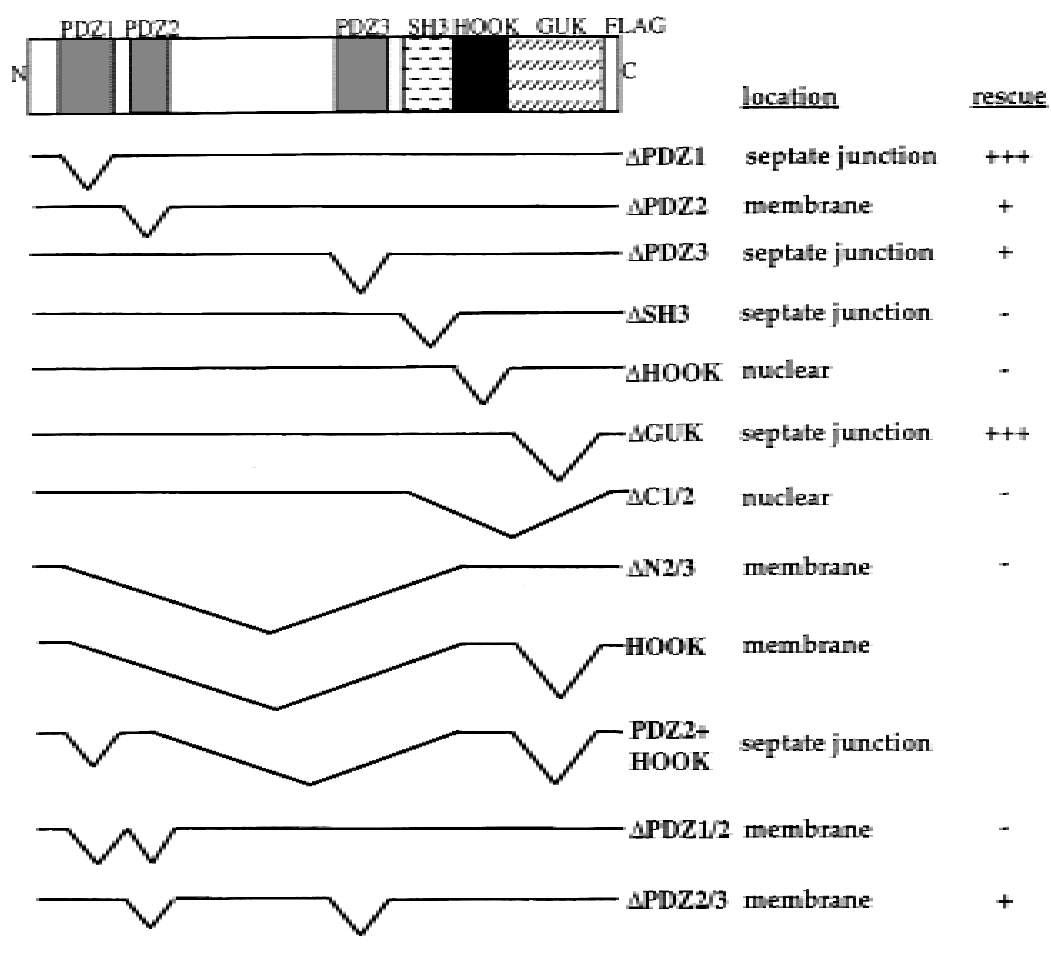

b

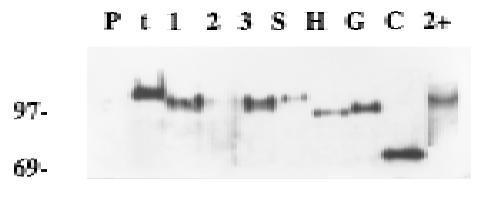

membrane in general as seen with $\mathrm{DIg}^{\Delta \mathrm{N} 2 / 3}-\mathrm{FLAG}$ (Fig. $2 d$ ), indicating that the PDZ2 domain is important for septate junction localization. The DIg ${ }^{\mathrm{N} 2 / 3}-\mathrm{FLAG}$ and DIg ${ }^{\text {GUK }}$-FLAG results implicate the HOOK domain as a membrane localization signal. A protein deleted for the $\mathrm{SH} 3$ through GUK domains, DIg ${ }^{\mathrm{Cl} 1 / 2}-\mathrm{FLAG}$, is not found at the membrane, but rather localizes to the nucleus (data not shown). In fact, deleting just the HOOK domain (DIg ${ }^{\mathrm{HOOK}}$-FLAG) al so abolishes membrane localization and the protein is found in the nucleus (Fig. 2e). Additionally, a peptide composed of only the HOOK domain fused to the amino terminus, HOOKFLAG, is distributed throughout the membrane in a pattern similar to that seen with DIg ${ }^{\text {PDZ2 }}$-FLAG (Fig. 2f).

The results show that two domains are required for localizing DIg to the septate junctions: (1) the HOOK domain is necessary for membrane targeting, and (2) PDZ2 is needed to refine the membrane localization to the septate junctions. To test this conclusion, a construct was made encoding only the PDZ2 and HOOK domains fused to the amino terminus, PDZ2 + HOOKFLAG. The minimal construct encoding only these two domains, $\sim 30 \%$ of the Dlg protein, is sufficient for normal localization to septate junctions (Fig. 2g).

Rescuing the structural defects and overgrowth phenotype of the dlg genetic null

Our analysis of the subcellular localization of mutant DIg proteins was carried out in the presence of endogenous normal DIg to ensure normal formation of the epithelial junctional complexes. To determine which DIg domains are required for the formation of functional cell contacts, the DIg-FLAG deletion constructs driven by the 69B GAL4 driver were placed in a background hemizygous for dlg $^{\mathrm{m} 52}$, which behaves as a genetic null allele and encodes a severely truncated protein predicted to contain only PDZ1 and PDZ2 domains (Woods et al. 1996). Imaginal wing discs from larvae of these genotypes were analyzed at the light microscope level (Fig. 3). Imaginal discs from dlgm52 animals are composed of a dense mass of multilayered, noncolumnar epithelial cells that lack septate junctions and apicobasal polarity as demonstrated by the redistribution throughout the 

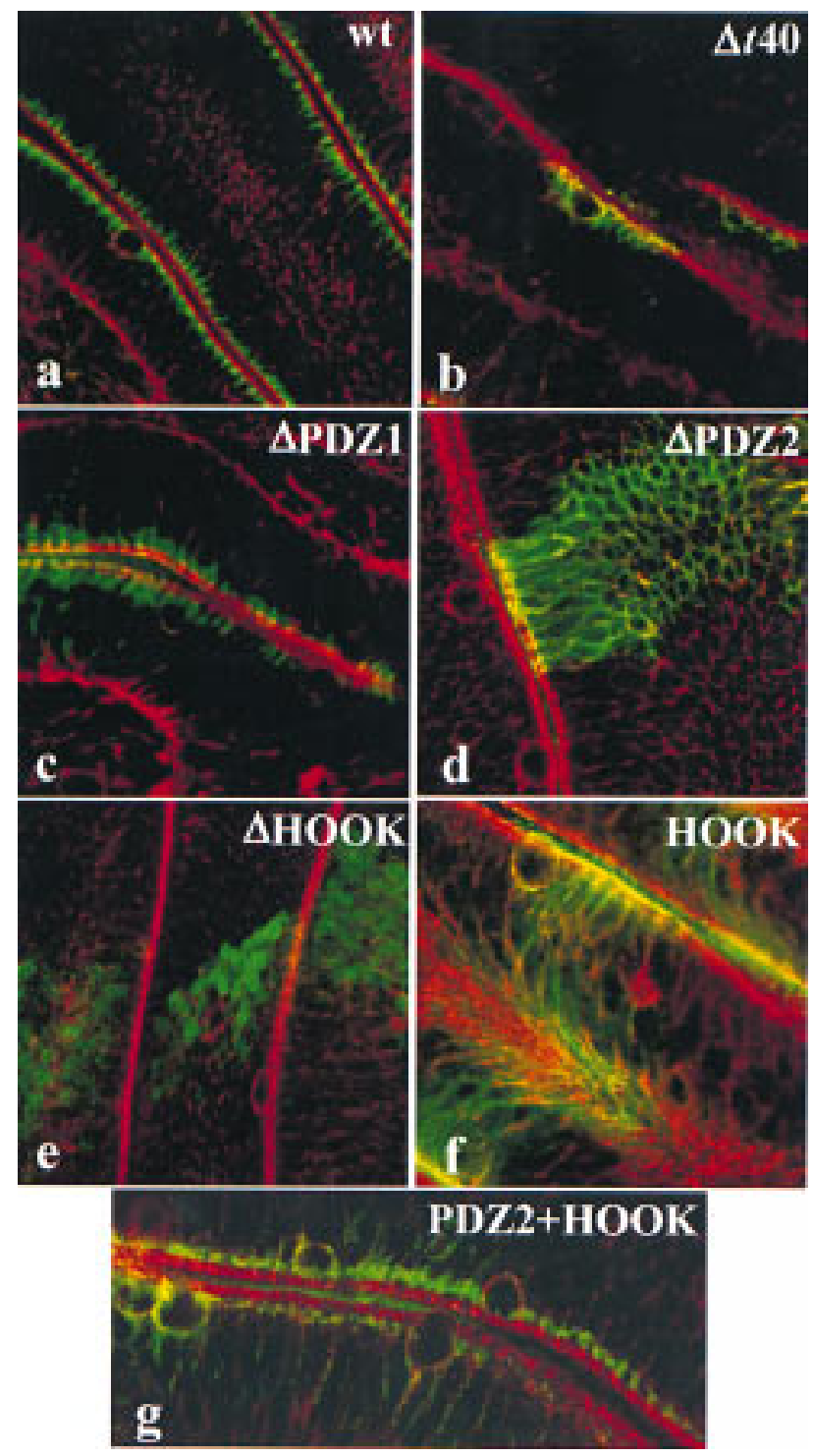

Figure 2. Subcellular localization of DIg-deletion proteins in wing discs expressing normal endogenous DIg analyzed by confocal microscopy. All images are of folds within the epithelial layer that result in an apical surface facing another apical surface. Large, dividing nuclei in addition to the actin band at the adherens junctions denote the apical faces. Filamentous actin was detected with rhodamine-phalloidin (red) and the DIg-deletion proteins were visualized using anti-FLAG M2 monoclonal antibodies (green), except in (a) where green staining corresponds to endogenous DIg. (a) Wild-type (magnification, 800x) (A) apical surfaces; (B) basal end of the folds; (b) $\triangle$ t40-FLAG (1400X); (c) $\triangle$ PDZ1-FLAG (1200X); (d) $\triangle$ PDZ2FLAG (1200x); (e) $\triangle$ HOOK-FLAG (1000x); (f) HOOK-FLAG (1400x); (g) PDZ2 + HOOK-FLAG (1400X). N ote that the stripe of protein produced from the Ptc-driver is out of register in adjacent folds $(b, d-f)$.

membrane of proteins that normally have junctionally restricted localization patterns [e.g., filamentous actin and Coracle (Cor), Fig. 3a; Woods et al. 1996]. In this set of experiments we assayed only two DIg functions: the ability of the protein to restore api cobasal polarity and to regulate growth of the epithelium. Using this approach we have found that the domains fall into the following three categories.

Dispensable domains Wing discs from dlg larvae producing the DIg ${ }^{\Delta U K_{-}}$FLAG protein exhibit the charac-
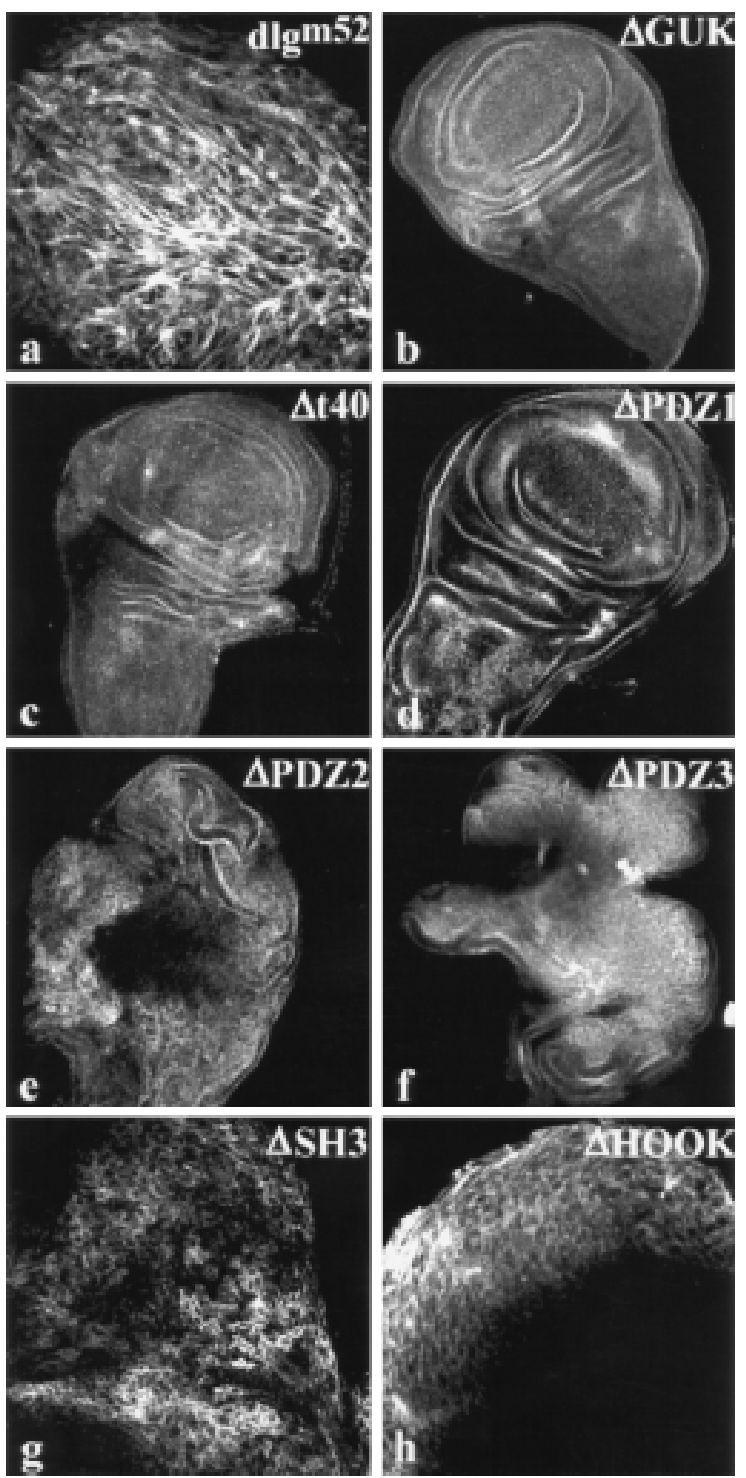

Figure 3. Ability of DIg-deletion proteins to rescue the structural defects and the overgrowth phenotype of the dlg genetic null. Filamentous actin was visual ized with rhodamine-phal loidin, except in (a) where the staining corresponds to the septate junction protein Cor, which is redistributed throughout the membrane in the dlg null al lele that lacks septate junctions. (a) disc tissue from a larva hemizygous for the genetic null allele $\mathrm{dlg}^{\mathrm{m} 52}$ (magnification, 400x); (b) completely rescued wing disc from a dlgm52 larva expressing $\triangle$ GUK-FLAG (200x); (c) $\Delta$ t40FLAG (200x); (d) $\triangle$ PDZ1-FLAG (200x); (e) $\triangle$ PDZ2-FLAG (200x); (f) $\triangle$ PDZ3-FLAG (200x); (g,h) the disc tissue from larvae expressing $\triangle$ SH3-FLAG and $\triangle$ HOOK-FLAG resemble the epithelium from the dlgm52 larva (a). 
teristic folds and shape of a wild-type disc (Fig. 3b) in contrast to discs isolated from siblings that do not con-

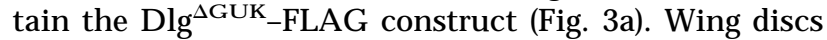
with DIg ${ }^{\Delta t 40}-F L A G$ (Fig. 3c) or DIg ${ }^{\mathrm{PDZ}}-$ FLAG (Fig. 3d) are rescued to essentially the same extent as those producing the DIg ${ }^{\text {GUK }}$-FLAG protein (Fig. 3b).

A picobasal polarity of the imaginal disc epithelium and the normal api cobasal local ization of membrane proteins are dependent on the presence of the DIg protein (Woods et al. 1996, 1997). To test whether the DIg ${ }^{\Delta U K_{-}}$ FLAG protein restores the normal distribution of proteins in the dlgm52 mutant, we analyzed the subcellular localization of other junctional proteins by confocal microscopy in rescued imaginal discs (Fig. 4). In wild type, the proteins Cor and Fasciclin III (FaslII) are located at septate junctions, whereas Drosophila Cadherin (DEC ad) and a circumferential band of filamentous actin are localized at the adherens junctions (Fehon et al. 1994; Oda et al. 1994; Woods et al. 1997). In imaginal discs from dlg ${ }^{\mathrm{m} 52}$ animals these proteins lose their normal pattern of distribution and instead are found over the entire plasma membrane (Woods et al. 1997). In the rescued dlg ${ }^{\mathrm{m} 52}$ imaginal discs, Cor (Fig. 4b) and Faslll (Fig. 4d) are localized at the membrane in a normal pattern at a level corresponding to septate junctions, just basal to the adherens junction protein DECad (Fig. 4a) and the apical actin band (Fig. 4c).

Imaginal discs from homozygous dlgm52 larvae, in which the epithelial defects and overgrowth phenotypes were rescued by the $\mathrm{DIg}^{\Delta \mathrm{t} 4 \mathrm{O}_{-}}$FLAG, $\mathrm{DIg}^{\Delta \mathrm{GUK}}-\mathrm{FLAG}$, and DIg ${ }^{\triangle P D Z 1}-F L A G$ proteins, were analyzed by el ectron microscopy to determine whether septate junctions were formed (Fig. 5). Expression of the DIg ${ }^{\Delta \text { UK }_{-}}$-FLAG (Fig. 5a), $\mathrm{DIg}^{\mathrm{At} 4 \mathrm{O}}-\mathrm{FLAG}$, or DIg ${ }^{\mathrm{PDZ1}}-\mathrm{FLAG}$ (data not shown) proteins results in tall, columnar epithelial cells similar to those of wild type. In each of the rescued discs, there is normal epithelial structure with cells connected by well-formed adherens and septate junctions (Fig. 5d-f).

Domains required for growth control but not epithelial structural integrity DIg-FLAG proteins deleted for either PDZ2 or PDZ3 partially rescue the $\mathrm{dlg}^{\mathrm{m} 52}$ phenotype; the discs appear to be a mosaic of columnar and cuboidal epithel ial tissue. However, the partially rescued discs are larger than wild-type discs apparently as a result of overproliferation of the epithelium (Fig. 3e,f). In these partially rescued wing discs there are regions of flat, singlelayered epithelium as well as highly folded, multilayered areas (Figs. 4 and 5). The multilayered regions represent the overgrown tissue, yet the cells appear epithelial in that they have clear apicobasal polarity and are connected by normal apical junctions (Fig. 5g,h). $M$ any cells within these partially rescued discs appear cuboi dal in shape compared with the tall, columnar cells

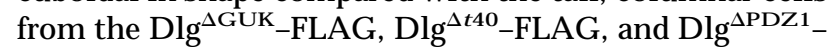
FLAG rescued discs (Fig. 5).

Although a DIg protein missing PDZ1 can rescue the dlg null disc phenotype and a DIg protein deleted for PDZ2 can rescue at least the epithelial defects observed in the null mutation, a protein deleted for both PDZ1 and PDZ2, DIg ${ }^{\mathrm{PDZ} 1 / \triangle P D Z 2}-F L A G$, is unable to rescue any aspect of the dlg ${ }^{\mathrm{m} 52}$ phenotype (data not shown). This suggests that in the absence of PDZ2, PDZ1 can partially substitute for PDZ2 and that one of these PDZ domains must be present for complete DIg function. On the other hand, PDZ3 appears to have a separate function from PDZ2, because a protein deleted for both of these domains (DIg ${ }^{\mathrm{PDZ} 2 / \triangle \mathrm{PDZ3}}-\mathrm{FLAG}$ ) rescues to an extent similar to that of constructs missing either domain al one (data not shown).
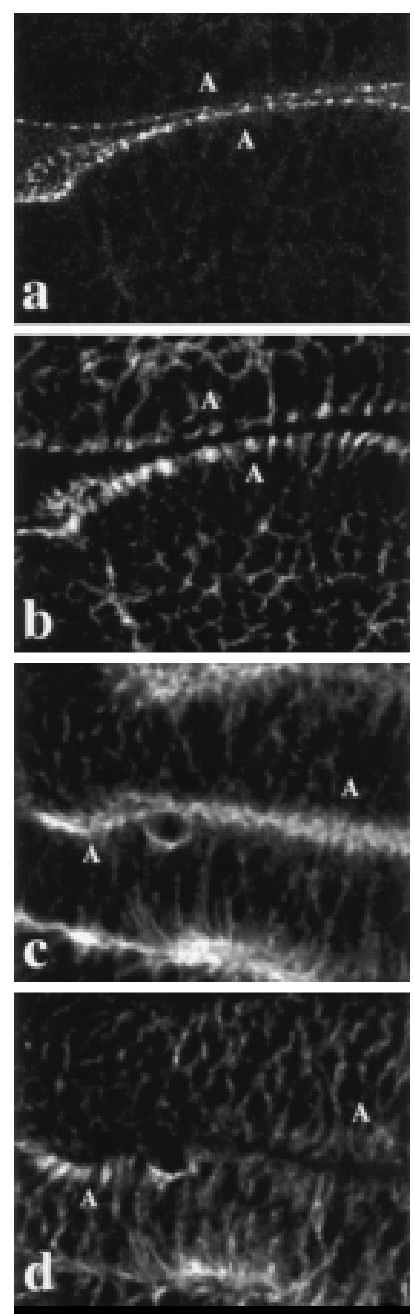

Figure 4. A bility of the DIg-del etion protein DIg ${ }^{\Delta G U K}-F L A G$ to restore apicobasal polarity in the dlg genetic null. The DIg ${ }^{\Delta G U K_{-}}$ FLAG construct was analyzed because of its ability to rescue the structural defects and overgrowth phenotype of the genetic null. The images show two apical surfaces facing each other within a fold of the wing disc epithelium. A wing disc stained with the septate junction marker Cor (a) detected with anti-Cor antibodies and with antibodies to the adherens junction protein DEC ad (b). N ote the Cor staining is located just basal to the DEC ad at the apical end of the cells. A wing disc stained with antibodies to FasllI (c), which is enriched in the cells at the level of the septate junctions, just basal to the adherens junction band of filamentous actin detected with rhodamine-phalloidin (d). (A) Apical. 


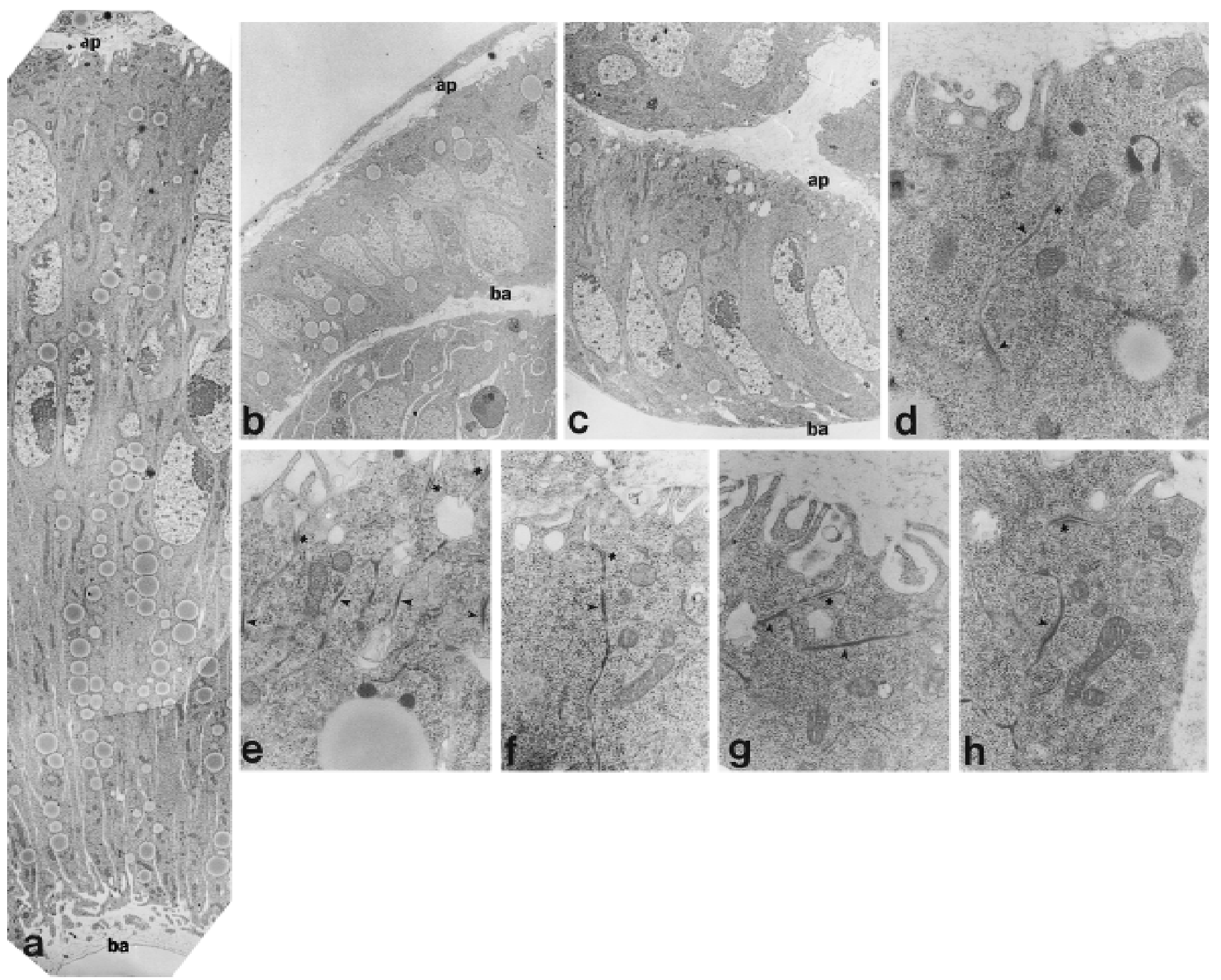

Figure 5. The ability of DIg del etion proteins to rescue septate junction formation in the dlg genetic null. TEM of wing disc epithelia. (ap) A pical; (ba) basal. (a-c) Rescue of dlg ${ }^{\mathrm{m} 52}$ epithelial structure with (a) $\triangle$ GUK-FLAG, (b) $\triangle P D Z 2-F L A G$, and (c) $\triangle P D Z 3-F L A G$. N ote the long, columnar epithelial cells from the $\triangle$ GUK-FLAG rescue (a). The epithelia from the $\triangle P D Z 2-F L A G$ (b) and $\triangle P D Z 3-F L A G$ (c) rescued discs have obvious apical and basal ends even though the cells are more cuboidal in shape. (d-h) Higher magnification of the rescued wing disc epithelia showing the apical junctions. (d) $\triangle$ GUK-FLAG; (e) $\Delta$ t40-FLAG; (f) $\triangle P D Z 1-F L A G$; (g) $\triangle P D Z 2-F L A G$; (h) $\triangle P D Z 3-F L A G$. Samples of septate junctions are marked with arrowheads and the apical adherens junctions with asterisks.

Essential domains The DIg ${ }^{\mathrm{N} 2 / 3}$-FLAG and $\mathrm{DIg}^{\mathrm{CC} 1 / 2_{-}}$ FLAG proteins show no rescue of epithelial structure or of the overgrowth phenotype produced by the dl $\mathrm{g}^{\mathrm{m} 52}$ al Iele, even though the proteins are easily detected by confocal microscopy (data not shown). Further testing of the DIg ${ }^{\triangle S H}{ }_{-F L A G}$ and DIg ${ }^{\triangle H O O K}$-FLAG constructs, which remove either the $\mathrm{SH} 3$ or HOOK domain, reveal that these two regions are critical for any measurable DIg protein function (Fig. 3g,h).

\section{Discussion}

In this study, we have undertaken the first analysis of the functional role in vivo of all of the domains (PDZs,
SH3, HOOK, and GUK) found in a new class of proteins, the MAGUKs, that link cellular signaling to the cytoskel eton. We identified those domains of the Drosophila MAGUK DIg that are important for septate junction localization within the context of normal epithelial structure provided by the presence of endogenous DIg. In the absence of functional DIg, which results in a disrupted epithelium, loss of septate junctions, and overgrowth, the addition of DIg-deletion derivatives identified an overlapping set of domains critical for rescuing these mutant phenotypes. Furthermore, this analysis clearly uncouples the role of DIg in growth regulation from the formation of epithelial structure and identifies a subset of domains required for these two processes. 
Subcellular targeting of DIg requires the PDZ2 and HOOK domains

The behavior of deletion constructs as well as isolated domains show that the HOOK domain acts as the membrane targeting signal for DIg. DIg derivatives that lack the HOOK domain are found in the nucleus and a protein that contains only HOOK localizes to the membrane. The membrane local ization of DIg via the HOOK domain could be through cytoskeletal interactions, because this domain of DIg and its closest mammalian homolog hDIg (Lue et al . 1996) contain sequences reported to bind protein 4.1 and ezrin (M arfatia et al. 1995, 1996), actin-associated proteins of the ERM superfamily. Targeting of the HOOK domain of hDIg (called I3) is solely dependent on the 4.1/ERM interaction (Lue et al. 1996). The Drosophila homolog of protein 4.1, Cor, colocal izes with DIg at septate junctions (Fehon et al. 1994) and would be a good candidate for a DIg anchor. However, DIg does not appear to be dependent on Cor for subcellular targeting and there is no evidence for a direct interaction between these two proteins (Fehon et al. 1997). In fact, the converse appears to be true: Cor, and another member of the protein 4.1 superfamily, Expanded, require DIg for appropriate local ization, al though possibly indirectly, because both depend on apicobasal polarity established by the formation of septate junctions (Woods et al. 1996). All of these results leave open the possibility that DIg is anchored to the membrane by an ERM protein other than 4.1 that has yet to be identified.

The nuclear localization of DIg derivatives lacking the HOOK domain may reflect nuclear targeting of the intact protein under some normal physiological conditions. A nother MAGUK, ZO-1, that is usually localized at tight junctions, has been reported to accumulate in the nucleus in subconfluent cell cultures, at sites of wounding in cultured epithelial cells, and in intestinal epithelial cells at the outer villus tip (Gottardi et al. 1996). Although DIg has not been observed in the nucleus in any of the tissues or stages we have examined, it is conceivable that such a localization is transient or occurs at a very limited time or circumscribed location, so has been missed. Alternatively, the nuclear localization may be simply a default state for the DIg protein when its primary localization signal is removed, and has no physiological significance because this would never occur in wild type. Because overexpression of the nucl ear form of DIg has no phenotypic consequences, we favor the second hypothesis.

In the absence of PDZ2, DIg protein is distributed throughout the membrane and not specifically localized to the septate junctions. However, a minimal construct consisting of PDZ2 and the HOOK domain allows localization to these junctions. Therefore the PDZ2 domain is necessary to refine the distribution of membrane-bound DIg to the septate junction. This targeting mechanism may involve dimerization with endogenous DIg or binding to an as-yet-unidentified transmembrane protein. Dimerization of the mammalian MAGUK PSD-95 is achieved through head-to-head multimerization by di- sulfide linkage of cysteines at the amino-termini (Hsueh et al. 1997). However, DIg does not contain these cysteine residues and the presence of the amino terminus in the DIg-FLAG derivatives has no influence on subcellular localization. PDZ1-2 domains are known to bind and cluster Shaker-like $\mathrm{K}^{+}$channel subunits and other transmembrane receptors (Kim et al. 1995, 1996). Membrane targeting of hDIg involves the interaction of PDZ1-2 with the carboxyl terminus of a Shaker-like subunit (Lue et al. 1996), and evidence for DIg clustering activity of Shaker channels has recently been demonstrated at Drosophila neuromuscular junctions in vivo (Tejedor et al. 1997). But although DIg PDZ1-2 domains mediate the binding to and clustering of Shaker channels, this interaction is insufficient for targeting the complex to the neuromuscular junctions (T ejedor et al . 1997). This finding is consistent with our results that indicate the necessity of the HOOK domain for proper subcellular localization. Collectively, the data suggest a mechanism for DIg sucellular localization in which the most critical step is membrane targeting mediated by the HOOK domain, possibly through interaction with the cytoskeleton, followed by refined subcellular localization mediated by PDZ2 via channel or membrane protein binding and clustering (Fig. 6). In a similar fashion, the erythrocyte MAGUK p55 all ows formation of a subcortical protein complex that links the membrane with the cytoskel eton through binding of both protein 4.1 (via HOOK; Marfatia et al . 1995) and the transmembrane protein glycophorin C (via PDZ; Marfatia et al. 1995; Songyang et al. 1997).

By examining a deletion series in Drosophila imagi nal discs, we are able to demonstrate the requirement of both PDZ2 and HOOK domains of DIg for normal subcellular localization in vivo. This confirms and extends the analysis of Lue et al. (1996), who showed that the PDZ1-2 or HOOK (I3) domains of hDIg can function independently to localize exogenous hDIg to the basolateral membrane of permeablized cells in vitro (Lue et al. 1996). The fact that DIg needs both of these domains for proper subcellular localization, whereas hDIg can Iocalize properly with either one of them, may be related to the fact that the normal subcellular location of DIg is at the septate junction, a much more precise localization than the much larger basolateral surface to which hDIg localizes. The need for both domains acting in concert probably al so reflects a difference in subcell ular targeting in vivo as opposed to local ization requirements in vitro.

\section{Functional analysis of the MAGUK domains}

The PDZ domains DIg proteins deleted for any of the PDZ domains were able to rescue epithelial defects caused by the genetic null allele dlg $^{\mathrm{m} 52}$, indicating that none of the three PDZ domains is absol utely required for apicobasal polarity. Unlike DIg deleted for PDZ2 or $\mathrm{PDZ3}$, the DI $\mathrm{g}^{\mathrm{PDZ1}}$ protein rescues the overgrowth phenotype in addition to epithelial structure, demonstrating that PDZ1 is unnecessary for any of the functions as- 


\section{a}

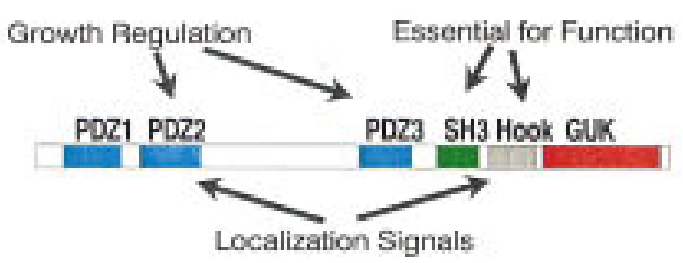

b

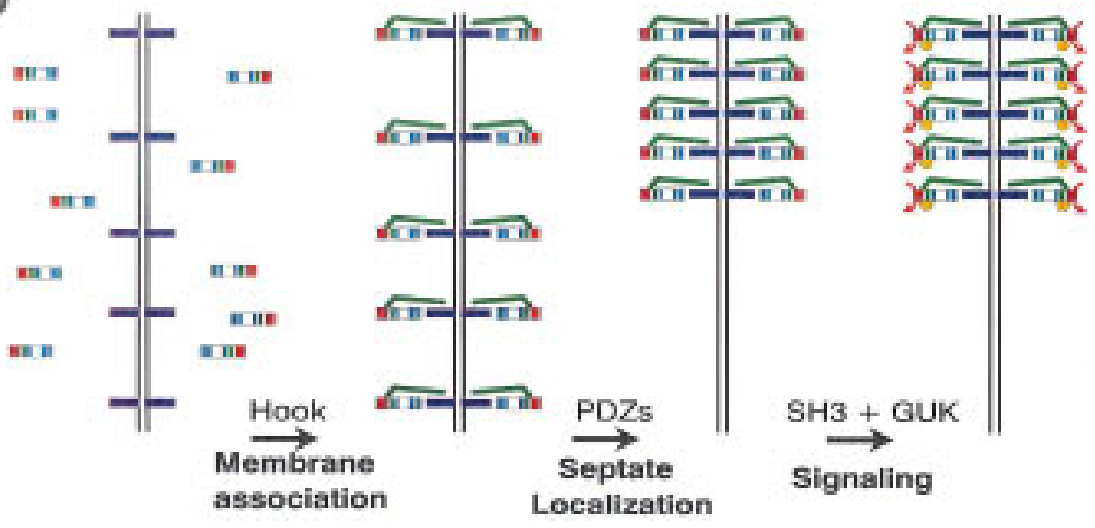

Figure 6. Model of Dlg function. (a) A summary of the function of each of the domains. (b) A three-step model of DIg localization to the septate junctions and binding of the proteins important for structure and growth regulation. Step 1: Binding of the HOOK domain to a protein 4.1-like protein (green line) and membrane localization. Step 2: Transmembrane protein (dark blue rectangle) binding to PDZ1/2 and clustering at the septate junction. Step 3: Stabilization and binding of proteins involved in additional functions such as growth regulation. The relative order of these steps is arbitrary. sayed for in this study. However, deleting both PDZ1 and PDZ2 completely abolishes rescue of the null phenotype, indicating that PDZ1 and PDZ2 have overlapping functions that allow them to substitute for one another under our assay conditions. In contrast, a PDZ2/3 deletion rescues to an extent similar to the deletion of either PDZ2 or PDZ3 al one, suggesting that these two domains have independent rather than redundant functions. This is consistent with the finding that PDZ1 and PDZ2 are structurally very similar in all MAGUKs and evolutionarily distinct from PDZ3 (Fanning and Anderson 1997). In addition, PDZ1/2 form a single, proteaseresistant module separate from PDZ3 (Lue et al. 1996; Marfatia et al. 1996).

The $\mathrm{SH} 3$ and HOOK domains The $\mathrm{SH} 3$ domain, though not required for septate junction localization, is critical for septate junction formation. A DIg protein deleted for only the $\mathrm{SH} 3$ domain was unable to restore any DIg function. This implies that the $\mathrm{SH} 3$ domain is essential for establishment or maintenance of septate junctions, consistent with our previous observation that an amino acid substitution in the SH3 domain (Leu ${ }^{632}$ to Pro) causes loss of septate junctions in prol iferating cells and leads to the overgrowth phenotype (Woods and Bryant 1991). However, the overgrowth phenotype caused by this mutation could be an indirect effect attributable to loss of septate junctions resulting in loss of apicobasal polarity. The absolute requirement of $\mathrm{SH} 3$ for function was surprising because it was not necessary for protein targeting.

In contrast, the requirement of HOOK is probably a direct consequence of this domain's importance for targeting DIg to the membrane. Without the HOOK do- main, DIg does not reach the membrane and septate junctions are not formed, resulting in the lack of epithelial structure and overgrowth. Our data support the idea that HOOK is critical not only for MAGUK subcellular localization in vivo but, as a consequence of this function, also for the integrity of the cytoskeleton and the control of growth.

The GUK domain The most carboxy-terminal MAGUK domain is a region with high similarity to the enzyme guanylate kinase; however, substantial enzymatic activity has not been demonstrated for any MAGUK and the function of this domain has remained elusive. Most MAGUKs have altered or missing critical residues in the GUK domain compared with authentic guanylate kinase. Furthermore, a Caenorhabditis elegans lin-2 transgene that is mutated to produce a GUK domain unable to bind ATP, or mutated at residues critical for GMP binding, can rescue the vulval ess phenotype caused by lin-2 mutations (Hoskins et al. 1996). Our data indicate that the GUK domain is not necessary for DIg function as long as enough of the "GUKless" DIg protein is provided. The DIg derivative lacking the GUK domain

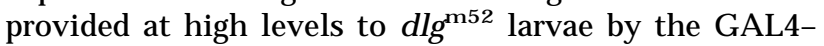
UAS system results in imaginal discs indistinguishable from those of wild type. In imaginal discs from these larvae, the adherens junction components actin and DECad, and the septate-enriched proteins Cor and FasIII, show normal subcellular localization. If, on the other hand, the rescue experiment is done at a lower temperature $\left(18^{\circ} \mathrm{C}\right)$ to produce lower quantities of GAL4 resulting in less DI $\mathrm{g}^{\mathrm{AGUK}}$ protein, rescue of the $\mathrm{dlg}^{\mathrm{m} 52}$ al lele is greatly reduced (data not shown). These data could explain the temperature-sensitive overgrowth phenotype 
of the $\mathrm{dlg}^{\mathrm{XI}-2}$ allele, which produces an extremely low level of protein truncated just prior to the GUK domain (Woods et al. 1996). However, based on the phenotype of recovered pharate adults, the GUK domain does appear to play a negative regulatory role in DIg function (data not shown) because a large truncation within the GUK domain of DIg leads to a protein with more wild-type function than one with a smaller truncation. This negative regulation may occur through binding of another protein. Indeed, a novel protein has been shown recently to bind the GUK domain of the mammalian synapseassociated MAGUKs, PSD95/SAP90 and Chapsyn 110 (Kim et al. 1997).

\section{Model of DIg function}

MAGUKs are postulated to function as mediators between cell signaling and the cytoskeleton. ZO-1 links the membrane to the cytoskeletal network by binding both spectrin (Itoh et al. 1991) and the transmembrane protein occludin (Furuse et al. 1994). ZO-1 localization to tight junctions is dependent on EGF-R phosphorylation and an intact actin cytoskel eton, and the actin-binding proteins spectrin and ezrin change their subcellular distribution in A431 human epidermal carcinoma cells in response to EGF treatment (Van Itallie et al. 1995). Similarly, the link between signaling and cytoarchitecture has been elegantly demonstrated in C. elegans by showing the dependence of proper vulval induction on Let-23 receptor localization to the cell-cell junctional complex (Hoskins et al. 1996; Simske et al. 1996). Our data show that the HOOK and PDZ2 domains are necessary for localization of DIg to the septate junctions, suggesting that, based on the described binding partners of these domains, the cytoskel eton and junctional membrane proteins are important components for junction morphogenesis, maintenance of apicobasal polarity, and localization of a signaling pathway controlling cell proliferation.

The function of the GUK domain in DIg is mysterious because, despite the obvious similarity of this domain to authentic guanylate kinases, it lacks this catalytic activity (S.M. Marfatia and A.H. Chishti, pers. comm.), possibly because of a 3-amino-acid deficiency in the region corresponding to the ATP-binding domain in authentic guanylate kinases (Woods and Bryant 1991). The work described in this paper suggests that the GUK domain, though not an active guanylate kinase, may act as a negative regulator, inhibiting the function of the rest of the protein in controlling cell proliferation.

Excess cell proliferation is accompanied by loss of epithelial structure in dlg mutants as well as in other neoplastic overgrowth mutants of Drosophila and many kinds of human cancer. One simple explanation for this association is that the cell interactions controlling proliferation are mediated by signaling complexes localized at cell junctions (for review, see Woods and Bryant 1993) and that breakdown of the cell junctions renders the signaling compl exes ineffective. Because at least some controls on cell proliferation are negative, the loss of junc- tions could lead to excess proliferation. Our results, however, suggest that the function of DIg in maintaining septate junction structure can be genetical ly separated from its role in controlling cell proliferation. Deletions of the PDZ2 and/or PDZ3 domains lead to excess proliferation without a loss of epithelial or junctional structure, mimicking the phenotype of another class of mutations called hyperplastic overgrowth mutations (Watson et al. 1994). This shows that the effect of dlg mutations in causing excess proliferation may not be an indirect consequence of loss of junctional structure, but may reflect a direct role of the DIg protein in the signaling events that control proliferation. We are now in the process of characterizing this novel signal transduction pathway required for cell polarity and growth regulation.

\section{Materials and methods}

DNA constructs and site-directed mutagenesis

The parent plasmid used for all del etion mutagenesis reactions was a dlgA cD N A fragment, -143 to 2805 bp, containing 143 bp of the $5^{\prime}$ untranslated region and the sequences encoding the first 935 amino acids of DIg with an in-frame FLAG epitope tag followed by a stop codon at the carboxyl terminus ( $\mathrm{Dlg}^{\mathrm{t} 4 \mathrm{C}_{-}}$ FLAG). This isoform contains a very small exon that encodes 15 additional amino acids between amino acids 751 and 764 of the published sequence (Woods and Bryant 1991). The ExSite PCRBased Site-Directed M utagenesis Kit (Stratagene, La Jolla, CA) was used to create most of the deletion constructs. This technique uses reverse PCR by anneal ing primers in opposite orientations on different strands of the plasmid, with the $3^{\prime}$ end of each oligonucleotide abutting the region to be deleted. This allows amplification of the whole plasmid minus the deleted sequences. The methylated parental plasmid is digested to small fragments with Dpnl whereas the ends of amplified plasmid are PFU-polished and ligated. Plasmids from colonies of Escherichia coli DH5a (Life Technologies, Gaithersburg, MD) transformed with the mutagenesis mixture were screened for the deletions by restriction digest and the deletion junctions sequenced to ensure the coding region was in frame. To ensure that no PCR-induced mutations occurred during the deletion mutagenesis, the smallest restriction fragment surrounding the deletion junction that was subjected to PCR was swapped with the analogous restriction fragment of the parent plasmid and that region was sequenced.

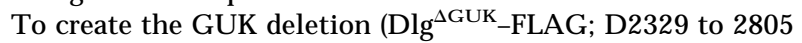
bp), a modified version of the unique site-elimination technique (Deng and Nickol off 1992), Chameleon Double-Stranded, SiteDirected Mutagenesis (Stratagene) was used to generate an EcoRI site at the $5^{\prime}$ end of the GUK domain (2325-2327 base pairs), using an oligonucleotide from base pairs 2312-2339 that converts GAGGCC to GAATTC. The EcoRI fragment containing GUK, 2329-2805 base pairs, was removed by restriction digest and the remaining plasmid recircularized. A fragment encoding only the HOOK domain (HOOK-FLAG; 2002-2340 bp) was created by using the Chameleon Double-Stranded, SiteDirected M utagenesis Kit (Stratagene) to generate an EcoRI site at the $5^{\prime}$ end of the GUK domain in DIg ${ }^{\mathrm{N} 2 / 3}-\mathrm{FLAG}$, as described above in the DIg ${ }^{\Delta U K_{-}}$FLAG construct, removing the GUK domain by restriction digest, and recircularizing the remaining plasmid. The del etion junctions were sequenced to ensure the coding regions were in frame. The DIg ${ }^{\mathrm{PDZ} 1 / \triangle \mathrm{PDZ}}{ }_{-}$ FLAG construct was made by creating a Sall site at the $5^{\prime}$ end of 
PDZ1 in the parent plasmid (bp 108) using the Chameleon Double-Stranded, Site-Directed Mutagenesis Kit, removing the Sall fragment (109-883 bp) by restriction digest, and religating the remaining plasmid.

The construct encoding the PDZ2 and HOOK domains (PDZ2 + HOOK-FLAG) was made by PCR-amplifying the HOOK-FLAG sequences from the HOOK-FLAG construct with a Sall site added to the $5^{\prime}$ end of the HOOK-encoding sequence, and swapping the Sall-Xbal fragment with the Sall(126 bp 3' of PDZ2)-Xbal(40 bp 3' of FLAG/stop) fragment from DIg ${ }^{\text {PDZ1 }}$ FLAG. The entire amplicon was sequenced to ensure that no PCR-induced mutations occurred and that the coding region remained in frame.

The DIg ${ }^{\mathrm{PDZ} 2 / \triangle \mathrm{PDZ}}$-FLAG construct was made by swapping the BamHI(184 bp 5' of coding region)-Sall(126 bp 3' of PDZ2) fragment encoding the amino terminus and PDZ1 domain from DIg ${ }^{\mathrm{PDZ2}}$-FLAG with the BamHI(184 bp $5^{\prime}$ of coding region)Sall(126 bp 3' of PDZ2) fragment from DIg SDZ3 $^{\text {PDLAG. }}$

The BamHI-Xbal fragments from all constructs were then subcl oned into the BgllI-Xbal sites of the P-element tranformation vector pUAST (Brand and Perrimon 1993).

\section{Production of transgenic flies and immunocytochemistry}

Germ-line transformants of all pUAST-DIg-FLAG constructs were obtained by injecting $5 \mathrm{mg}$ of Qiagen-purified DNA and helper plasmid pP25.7wc into white (w) embryos using the methods of Rubin and Spradl ing (1982). The insert of each transformant, identified by red eye color, was mapped to a chromosome by mating to the $w ; X a / S m 5$ TM3 mapping strain. Six independent lines were established for each construct, with at least one from each set mapping to each of chromosomes 1-3.

Transformants were crossed to the GAL4 enhancer-trap line 69B [ $\mathrm{w}^{*} ; \mathrm{P}\left(\mathrm{w}^{\mathrm{tmW} . \mathrm{hs}}=\mathrm{GawB}\right) 69 \mathrm{~B} ;$ Brand and Perrimon 1993] to express DIg-FLAG derivatives at high levels throughout most of the wing disc, or to Ptc-driven GAL4 $\left[w^{*} ;\left(w^{+m W} \cdot h s=G\right.\right.$ awB $)$ ptc559.1; Drosophila Stock Center, Bloomington, IN ], to express the proteins at a very high level in a stripe along the anterior/ posterior compartment boundary. The 69B line drives expression in a somewhat patchy pattern with the majority of the disc containing relatively high levels and a few portions of the disc having lower levels. The Ptc-driver is useful for determining whether a transformant line expresses the transgene because the stripe of GAL4-induced protein on a background of no expression is easily detected by confocal microscopy. Third-instar larvae were dissected in Chan and Gehring Ringer's solution and the discs were fixed in $4 \%$ formal dehyde for $30 \mathrm{~min}$, rinsed twice with $1 \times$ PBS, and incubated for $1 \mathrm{hr}$ in block [ $1 \times$ PBS, $2 \%$ bovine serum al bumin, $0.2 \% \mathrm{~N} \mathrm{P}-40,0.02 \%$ sodium azide]. The discs were incubated in a 1:1000 dilution of M2 anti-FLAG monoclonal overnight at $4^{\circ} \mathrm{C}$ and washed for $5 \mathrm{~min}, 3$ times in block. The tissue was incubated for $2 \mathrm{hr}$ at room temperature in Cy2- or fluorescein isothiocyanate (FITC)-conjugated secondary antibody (Jackson ImmunoResearch Laboratories, Inc., West Grove, PA) and rhodamine-phalloidin for detection of filamentous actin (M olecular Probes, Inc., Eugene, OR). The subcellular localization of the DIg-FLAG derivatives was analyzed by confocal microscopy using a BioRad MRC 1024 with a Nikon inverted microscope.

\section{Rescue of dlg $\mathrm{g}^{\mathrm{m} 52}$, confocal and el ectron microscopy}

Male flies homozygous for the dlg-FLAG deletion transgenes were crossed to y w dlg ${ }^{\mathrm{m} 52} /$ Binsn; 69B/ + virgin females. Male third-instar larvae with yellow mouthhooks (y, dl g ${ }^{\mathrm{m} 52} / \mathrm{Y} ; 69 \mathrm{~B} /+$ or 69B) were dissected in Chan and Gehring Ringer's solution and the wing discs prepared for confocal microscopy as described above. To determine the localization of junction-associated proteins, discs were stained with antibodies against Cor (1:500; Fehon et al. 1994), DECad (1:200; Oda et al. 1994), and Fas III (1:500; Brower et al. 1980), followed by the addition of rhodamine-phalloidin and FITC-conjugated secondary antibodies. Endogenous DIg was detected using anti-DIg antibodies (Woods and Bryant 1991) di luted 1:500 and Cy2-conjugated secondary antibodies. The samples were analyzed by confocal microscopy as described above.

Tissues were prepared for electron microscopy by fixing in $4 \%$ glutaral dehyde in $0.125 \mathrm{~m}$ cacodylate buffer for $2 \mathrm{hr}$, washed 3 times, and stored in $1 \times$ PBS at $4^{\circ} \mathrm{C}$. Samples were then fixed for 1-2 hr in 4\% osmium tetroxide, washed, dehydrated in a graded ethanol series, and embedded in Polybed 812 resin (Polysciences, Inc., Warrington, PA). Ultrathin sections were stained with uranyl acetate and lead citrate and analyzed on a Zeiss EM $10 \mathrm{C}$ electron microscope.

\section{Western blot protein analysis}

Male dlg-FLAG transformants were crossed to virgin females homozygous for the Ptc-driven GAL4. Six larval heads from each cross were homogenized in $50 \mathrm{ml}$ of sample buffer $(0.2 \mathrm{M}$ Tris- $\mathrm{HCl}$ at $\mathrm{pH} 6.8,5 \%$ SDS, 30\% glycerol, $0.05 \%$ bromophenol blue) and equival ent samples ( 2 "'heads") el ectrophoresed on a $10 \%$ polyacrylamide gel, el ectrobl otted onto PVDF membrane, and probed for $1 \mathrm{hr}$ at room temerature with M 2 anti-FLAG monoclonal antibodies (IBI/Eastman Kodak, N ew Haven, CT) diluted 1:300 in block (1×PBS, $0.2 \%$ Tween $20,5 \%$ nonfat powdered milk). The bl ot was washed 3 times, 5 min each in $1 \times P B S$ and incubated in HRP-conjugated anti-mouse IgG secondary antibodies (Amersham Corp., Arlington Heights, IL) for $1 \mathrm{hr}$ at room temperature. The bl ot was washed 10 times, 3 min each and the proteins visualized by enhanced chemiluminescence (ECL Western Blotting Detection Reagents, Amersham Corp.).

\section{Acknowledgments}

We are grateful to Rick Fehon, Tadashi Uemura, and Danny Brower for providing antibodies, and M ike Boedighei mer and Ira Blitz for useful insights and helpful discussions. We also thank the Image Facility for their contribution to the EM work and the Optical Biology Core Facility for use of the confocal microscope. This investigation was supported by grant CA66263 from the $\mathrm{N}$ ational Cancer Institute of the $\mathrm{N}$ ational Institutes of Health and a Simons-M onroe Fund Grants-in-Aid of Research award to C.D.H. from the Scientific Research Society, Sigma Xi.

The publication costs of this article were defrayed in part by payment of page charges. This article must therefore be hereby marked "advertisement" in accordance with 18 USC section 1734 solely to indicate this fact.

\section{References}

A berle, H., H. Schwartz, and R. Kemler. 1996. Cadherin-catenin complex: Protein interactions and their implications for cadherin function. J. Cell Biochem. 61: 514-523.

Alley, M.R., J.R. M addock, and L. Shapiro. 1993. Requirement of the carboxyl terminus of a bacterial chemoreceptor for its targeted proteolysis. Science 259: 1754-1757.

Bar-Sagi, D., D. Rotin, A. Batzer, V. Mandiyan, and J. Schlessinger. 1993. SH3 domains direct cellular localization of signalling molecules. Cell 74: 83-91.

Brand, A.H. and N . Perrimon. 1993. Targeted gene expression as 
a means of altering cell fates and generating dominant phe notypes. Development 118: 401-415.

Brower, D.L., R.J. Smith, and M. Wilcox. 1980. A monoclonal antibody specific for diploid epithelial cells in Drosophila. Nature 285: 403-405.

Budnik, V., Y. Koh, B. Guan, B. Hartmann, C. Hough, D. Woods, and M. Gorczyca. 1996. Regulation of synapse structure and function by the Drosophila tumor suppressor gene dlg. Neuron 17: 627-640.

Cagan, R.L., H. Kramer, A.C. Hart, and S.L. Zipursky. 1992. The bride of sevenless and sevenless interaction: Internalization of a transmembrane ligand. Cell 69: 393-399.

Cohen, G.B., R. Ren, and D. Baltimore. 1995. Modular binding domains in signal transduction proteins. Cell 80: 237-248.

Dodane, V. and B. Kachar. 1996. Identification of isoforms of G proteins and PKC that colocalize with tight junctions. J. Membr. Biol. 149: 199-209.

Fanning, A.S. and J.M. Anderson. 1997. PDZ domains and the formation of protein networks at the plasma membrane. In Current topics in microbiology (ed. A. Pawsons). Academic Press, N ew York, NY. (In press.)

Fehon, R.G., K. Johansen, I. Rebay, and S. Artavanis-T sakonas. 1991. Complex cellular and subcellular regulation of Notch expression during embryonic and imaginal development of Drosophila: Implications for Notch function. J. Cell Biol. 113: 657-669.

Fehon, R.G., I.A. Dawson, and S. Artavanis-T sakonas. 1994. A Drosophila homologue of membrane-skel eton protein 4.1 is associated with septate junctions and is encoded by the coracle gene. Development 120: 545-557.

Fehon, R.G., D. Laleunesse, R. Lamb, B.M. McCartney, L. Schweizer, and R.E. Ward. 1997. Functional studies of the protein 4.1 family of junctional proteins in Drosophila. Soc. Gen. Physiol. Ser. 52: 149-159.

Froehner, S.C. 1993. Regulation of ion channel distribution at synapses. Annu. Rev. Neurosci. 16: 347-368.

Furuse, M., M. Itoh, T. Hirase, A. N agafuchi, S. Yonemura, and S. Tsukita. 1994. Direct association of occludin with ZO-1 and its possible involvement in the localization of occludin at tight junctions. J. Cell Biol. 127: 1617-1626.

Gottardi, C.J., M. Arpin, A.S. Fanning, and D. Louvard. 1996. The junction-associated protein, zonula occludens-1, localizes to the nucleus before the maturation and during the remodeling of cell-cell contacts. Proc. Natl. Acad. Sci. 93: 10779-10784.

Hoskins, R., A.F. Hajnal, S.A. Harp, and S.K. Kim. 1996. The C. el egans vulval induction gene lin-2 encodes a member of the MAGUK family of cell junction proteins. Development 122: 97-111.

Hsueh, Y.-P., E. Kim, and M. Sheng. 1997. Disulfide-linked head-to-head multimerization in the mechanism of ion channel clustering by PSD-95. Neuron 18: 803-814.

Itoh, M., S. Yonemura, A. Nagafuchi, and S. Tsukita. 1991. A 220-kD undercoat-constitutive protein: Its specific localization at cadherin-based cell-cell adhesion sites. J. Cell Biol. 115: 1449-1462.

Kim, E., M. Niethammer, A. Rothschild, Y.N. Jan, and M. Sheng. 1995. Clustering of Shaker-type $\mathrm{K}^{+}$channels by interaction with a family of membrane-associated guanylate kinases. Nature 378: 85-88.

Kim, E., K.O. Cho, A. Rothschild, and M. Sheng. 1996. Heteromultimerization and N MDA receptor-clustering activity of chapsyn-110, a member of the PSD-95 family of proteins. Neuron 17: 103-113.

Kim, E., S. N aisbitt, Y.P. Hsueh, A. Rao, A. Rothschild, A.M. Craig, and M. Sheng. 1997. GKAP, a novel synaptic protein that interacts with the guanylate kinase-like domain of the PSD-95/SAP90 family of channel clustering molecules. J. Cell Biol. 136: 669-678.

Kim, S.K. 1995. Tight junctions, membrane-associated guanylate kinases and cell signaling. Curr. Opin. Cell Biol. 7: 641649.

Kistner, U., C.C. Garner, and M. Linial. 1995. N ucleotide binding by the synapse associated protein SAP90. FEBS Lett. 359: 159-163.

Kooh, P.J., R.G. Fehon, and M .A.T. M uskavitch. 1993. Implications of dynamic patterns of Delta and $\mathrm{N}$ otch expression for cellular interactions during Drosophila development. Development 117: 493-507.

Kornau, H.C., L.T. Schenker, M.B. Kennedy, and P.H. Seeburg. 1995. Domain interaction between NMDA receptor subunits and the postsynaptic density protein PSD-95. Science 269: 1737-1740.

Lue, R.A., S.M. Marfatia, D. Branton, and A.H. Chishti. 1994. Cloning and characterization of hDIg: The human homologue of the Drosophila discs large tumor suppressor binds to protein 4.1. Proc. Natl. Acad. Sci. 91: 9818-9822.

Lue, R.A., E. Brandin, E.P. Chan, and D. Branton. 1996. Two independent domains of hDIg are sufficient for subcellular targeting: The PDZ1-2 conformational unit and an alternatively spliced domain. J. Cell Biol. 135: 1125-1137.

M arfatia, S.M., R.A. Lue, D. Branton, and A.H. Chishti. 1994. In vitro binding studies suggest a membrane-associated complex between erythroid p55, protein 4.1, and glycophorin C. J. Biol. Chem. 269: 8631-8634.

M arfatia, S.M., R.A. Lue, D. Branton, and A.H. Chishti. 1995. Identification of the protein 4.1 binding interface on glycophorin $\mathrm{C}$ and p55, a homologue of the Drosophila discs-large tumor suppressor protein. J. Biol. Chem. 270: 715-719.

Marfatia, S.M., J.H. Cabral, L. Lin, C. Hough, P.J. Bryant, L. Stolz, and A.H. Chishti. 1996. Modular organization of the PDZ domains in the human discs-large protein suggests a mechanism for coupling PDZ domain-binding proteins to ATP and the membrane cytoskel eton. J. Cell Biol. 135: 753766.

Müller, B.M., U. Kistner, R.W. Veh, C. Cases-Langhoff, B. Becker, E.D. Gundelfinger, and C.C. Garner. 1995. M olecular characterization and spatial distribution of SAP97, a novel presynaptic protein homologous to SAP90 and the Drosophila discs-large tumor suppressor protein. J. Neurosci. 15: 2354-2366.

N athke, I.S., L. Hinck, J.R. Swedlow, J. Papkoff, and W.J. N elson. 1994. Defining interactions and distributions of cadherin and catenin complexes in polarized epithelial cells. J. Cell Biol. 125: 1341-1352.

Niethammer, M., E. Kim, and M. Sheng. 1996. Interaction between the $C$ terminus of N MDA receptor subunits and multiple members of the PSD-95 family of membrane-associated guanylate kinases. J. Neurosci. 16: 2157-2163.

Oda, H., T. U emura, Y. Harada, Y. I wai, and M. Takeichi. 1994. A Drosophila homolog of cadherin associated with armadillo and essential for embryonic cell-cell adhesion. Dev. Biol. 165: 716-726.

Pemberton, L.F., A. Rughetti, J. Taylor-Papadimitriou, and S.J. Gendler. 1996. The epithelial mucin MUC1 contains at least two discrete signals specifying membrane localization in cells. J. Biol. Chem. 271: 2332-2340.

Rubin, G.M. and A.C. Spradling. 1982. Genetic transformation of Drosophila with transposable element vectors. Science 218: 348-353.

Schlessinger, J. 1994. SH2/SH3 signaling proteins. Curr. O pin. Genet. Dev. 4: 25-30. 
Simske, J.S., S.M. Kaech, S.A. Harp, and S.K. Kim. 1996. LET-23 receptor localization by the cell junction protein LIN -7 during C. elegans vulval induction. Cell 85: 195-204.

Sturtevant, M.A., M. Roark, J.W. O'N eill, B. Biehs, N. Colley, and E. Bier. 1996. The Drosophila rhomboid protein is concentrated in patches at the apical cell surface. Dev. Biol. 174: 298-309.

Takahisa, M., S. Togashi, T. Suzuki, M. Kobayashi, A. Murayama, K. Kondo, T. Miyake, and R. Ueda. 1996. The Drosophila tamou gene, a component of the activating pathway of extramacrochaetae expression, encodes a protein homologous to mammalian cell-cell junction-associated protein ZO-1. Genes \& Dev. 10: 1783-1795.

Tejedor, F.J., A. Bokhari, O. Rogero, M. Gorczyca, J. Zhang, E. Kim, M. Sheng, and V. Budnik. 1997. Essential role for dlg in synaptic clustering of Shaker $\mathrm{K}^{+}$channels in vivo. J. Neurosci. 17: 152-159.

Thomas, U., B. Phannavong, B. Muller, C.C. Garner, and E.D. Gundelfinger. 1997. Functional expression of rat synapseassociated proteins SAP97 and SAP102 in Drosophila dlg-1 mutants: Effects on tumor suppression and synaptic bouton structure. Mech. Dev. 62: 161-174.

Tomlinson, A., D.D. Bowtell, E. Hafen, and G.M. Rubin. 1987. Localization of the sevenless protein, a putative receptor for positional information, in the eye imaginal disc of Drosophila. Cell 51: 143-150.

Van Itallie, C.M., M.S. Balda, and J.M. Anderson. 1995. Epidermal growth factor induces tyrosine phosphorylation and re organization of the tight junction protein ZO-1 in A431 cells. J. Cell Sci. 108: 1735-1742.

Watson, K.L., R.W. Justice, and P.J. Bryant. 1994. Drosophila in cancer research: The first fifty tumor suppressor genes. J. Cell Sci. (Suppl.) 18: 19-33.

Woods, D.F. and P.J. Bryant. 1989. Molecular cloning of the lethal(1)discs large-1 oncogene of Drosophila. Dev. Biol. 134: 222-235.

- - . 1991. The discs-large tumor suppressor gene of Drosophila encodes a guanylate kinase homolog local ized at septate junctions. Cell 66: 451-464.

- - . 1993. A pical junctions and cell signalling in epithelia. J. Cell Sci. 17: 171-181.

Woods, D.F., C. Hough, D. Peel, G. Callaini, and P.J. Bryant. 1996. DIg protein is required for junction structure, cell poIarity, and proliferation control in Drosophila epithelia. J. Cell Biol. 134: 1469-1482.

Woods, D.F., J.-W. Wu, and P.J. Bryant. 1997. Localization of proteins to the apico-lateral junctions of Drosophila epithelia. Dev. Genet. 20: 111-118.

Zak, N.B. and B.Z. Shilo. 1992. Localization of DER and the pattern of cell divisions in wild-type and Ellipse eye imaginal discs. Dev. Biol. 149: 448-456. 


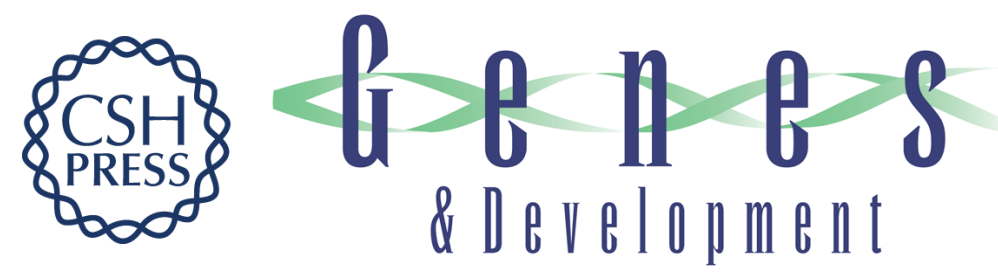

\section{Organizing a functional junctional complex requires specific domains of the Drosophila MAGUK Discs large}

Colleen D. Hough, Daniel F. Woods, Sangbin Park, et al.

Genes Dev. 1997, 11:

Access the most recent version at doi:10.1101/gad.11.23.3242

References

This article cites 50 articles, 26 of which can be accessed free at:

http://genesdev.cshlp.org/content/11/23/3242.full.html\#ref-list-1

\section{License}

Email Alerting

Receive free email alerts when new articles cite this article - sign up in the box at the top

Service right corner of the article or click here.

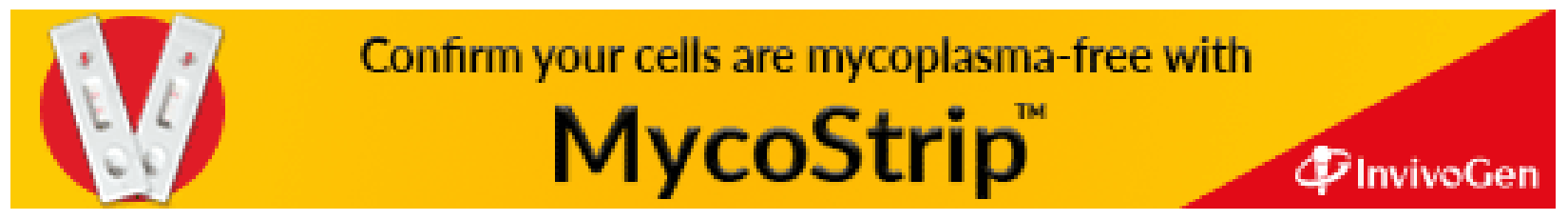

